\title{
Macroeconomic Factors and Birth of New Businesses in Developing Countries: Evidence from a Dynamic System GMM Approach
}

\author{
Othmane FAHIM ${ }^{1}$ * \\ Salma NAAMANE2
}

DOI: $10.24818 / \mathrm{mer} / 2021.06-05$

\begin{abstract}
This paper aims to discuss and determine the nature of relationship between the birth of new enterprises and macroeconomic factors in using a panel data of 73 developing countries for the period of 2006-2018. The study used panel corrected standard error approach (PCSE) and system generalized method of moments (GMM) approach. The main conclusions revealed that foremost economic growth, translated in terms of real gross domestic product per capita, and in terms of variation in demand, has proved to be a positive determining factor in the creation of enterprises. Furthermore, the population growth rate and inflation, while contributing positively to the creation of new enterprises, did not produce the effect that would have been expected, given the relatively low elasticity. Addition, the results also indicate that unemployment rate and employment vulnerability have small negative effects on new firms' creation.
\end{abstract}

KEYWORDS: economic growth, macroeconomic factors, birth of new firms, PCSE approach, GMM-system

JEL CLASSIFICATION: $C 23, M 13, O 11$

\section{INTRODUCTION}

Many theoretical and empirical perspectives and studies around the birth of new firms have emerged recently. Several scholars and social economists have taken interest into the belief that new enterprises play a crucial part in economy growth and development. New and young enterprises have always been the driving power to rising wages and performance rates due to openness to competition, new technology and innovation more than matured firms (Braunerhjelm, 2007).

Recent theoretical and empirical advancements have made this theoretical framework more relevant to analyze the relationship between entrepreneurship and macroeconomic environment by studying the nature of relationships between our studied variables. As a result, several macroeconomic variables influencing entrepreneurship have been considered based on these theoretical justifications (Sutaria \& Hicks, 2004). These include variables such as conditions of labour, changes in demand and the accessibility to a financial capital.

As a result, the use of several macroeconomic variables influencing entrepreneurship have been justified by these theoretical frameworks (Sutaria \& Hicks, 2004), such as labour market, accessibility to a financial capital.

\footnotetext{
1* Mohammed V University - Rabat (Department of Economics), Morocco, othmane.fahim@um5s.net.ma, corresponding author

${ }^{2}$ Moroccan Observatory of the Micro, Small and Medium Enterprise, Morocco, salma.naamane@gmail.com
} 
The purpose of this paper is to explore the relation between the macroeconomic factors (GDP growth per capita, unemployment, vulnerable employment, population growth, openness, and consumer price index) and birth business in developing countries for the period of 2006-2018 using the World Bank data. Panel corrected standard error (static estimation) approach and one step system generalized method of moments approach are used.

The current research investigated the issue with a new data set using improved econometric techniques. Moreover, in developing countries, this kind of study is not widespread, particularly with panel data of a large number of years. Furthermore, this study has considered the problem of heterogeneity and the findings of this research are new contributions to the existing literature.

We will dive more into the theoretical and empirical literature in Section 2. Section 3 will highlight the methodology used, namely the database, variables, and estimation methods. Section 4 is implied into discussing our new firms' patterns. Finally, Section 5 briefly concludes our results.

\section{THEORETICAL AND EMPIRICAL LITERATURE}

Taking into consideration the theoretical framework, Classic Growth Theory argues that physical limited resources and growing population will decrease the economic growth. However, unlike its precedent Neoclassical Growth Theory argues that technology advances, labour, and accumulation of human capital are the three main factors to economy growth.

New Growth Theory offered a fresh new perspective. It emphasizes the importance on knowledge, technology and innovation challenging the other old theories and projecting itself to a more modern world. Thus, the question remains: is this new theory overestimating the capacity of human capital in nurturing innovation and hence balancing diminishing returns? Within the context, the purpose of this paper is to answer this question through an empirical study. This could allude to whether socio-economic factor of ethnic heterogeneity hold an effect on the number of rising start-ups and created jobs across countries (Froyen, 2013).

The theoretical arguments that support these results are partly alluded to contributions by (Knight, 1921; Oxenfeldt, 1943) on the occupational choices of individuals. Indeed, the income choice theory of (Knight, 1921) produced the first insights linking unemployment to self-employment. The decision to become an entrepreneur is a reaction to either unemployment or poor job prospects (Thurik \& al., 2008). This relationship, which is analyzed according to two hypotheses, is still relevant today (Santarelli \& al., 2009):

The first hypothesis, named "push hypothesis", is based on the idea of (Knight, 1921) that individuals have to decide on how to allocate their time and capabilities between paid employment, unemployment and self-employment according to market prices. Through this aspect, individuals who observe unfavorable income will chose to be self-employed than unemployed since the latter is still considered the least desirable outcome (Oxenfeldt, 1943).

The second hypothesis, named "pull hypothesis", is a counterargument to its precedent, considering that low levels of unemployment allude to economic movement and available opportunities for new entrepreneurs (Carree, 2006; Choi \& Phan, 2006). Therefore, low unemployment would have a pull effect on individuals towards entrepreneurial activity. 
An analysis of both empirical literatures specifically on the determinants of entrepreneurial dynamics leads us to note that the latter once been applied in different fields seems to produce some disparate results. Indeed, studies devoted to this issue have been conducted using various exploratory data models on different units of analysis, such as sector and context of considered data panels (Sutaria \& Hiks, 2004). While respecting the relationship between entrepreneurship and labour market conditions, insights contained in the contributions of (Knight, 1921; Oxenfeldt, 1943) above have undergone important developments. (Fritsch \& Falck, 2007) observed a positive relationship between labour market conditions and new business creation only with short-term unemployment.

On the other hand, (Koellinger \& Thurik, 2009) have shown that the cycles that characterize entrepreneurship are positively affected by unemployment cycles and that entrepreneurship is a proven indicator of the business cycle as it causes the improvement of national income in the Granger sense. Concerning the influence of the evolution of business creation, the idea is developed that the entrepreneurial dynamic is also driven by the level of development of society and the business cycle through demand factors. The idea being that an increase in demand or the emergence of new demand encourages the start of a large number of new businesses. Increased demand for goods and services, attributed to population growth, growth in per capita income and changing tastes, leads to market expansion (Wenekers \& al., 2005; Keeble \& Wever, 1986) and is therefore associated with a high rate of business start-ups.

(Reynolds \& Storey, 1993) produced international results in a study analyzing the determinants of enterprise creation in the United States, Great Britain, Ireland, Italy, France, Sweden and Germany over the period time 1980-1990. These results revealed similarities in national rates of enterprise creation, as well as inter-regional differences across countries. Factors that significantly influenced enterprise creation regionally are population growth reflecting increased demand, the concentration of small businesses and the high rate of urbanization. (Tambunan, 1994) studied the high growth rate of small enterprise creation in Indonesia. The results of this study showed that the determining factor in the high rate of enterprise creation was the lack of employment and income prospects.

Indeed, it was revealed that the majority of production units created in the form of selfemployment were much more driven by a need for survival, suggesting to the author that the high growth rate of small enterprise creation was driving by socio-economic problems (poverty) rather than economic growth. (Audretsch \& Fritsch, 1994) produced a study for Germany in which they tried to verify Krugman's predictions, i.e., the relationship between the importance of increasing returns within a geographical area and the concentration of economic activity, measured by the birth of new enterprises. The results of their study revealed that in the period time 1986-1989, the birth rate of enterprises is higher in regions characterized with agglomeration effects and that population density has a significant impact on the rate of enterprise creation. It has also revealed some ambiguities in the relationship between unemployment and new enterprise creation. To conclude, the study confirmed that unemployment does not equal creation of new enterprises.

For its part, (Masuda, 2006) examined the regional characteristics that affect "latent entrepreneurship" in Japan. The results of this study concluded that two macroeconomic factors have a positive effect on "latent entrepreneurship", these are the unemployment rate and the income level. (Otsuka, 2008) shows that the influence of the labour market on enterprise creation in the two sectors differs according to whether it is assessed on the basis of 
the unemployment rate or the wage level. The unemployment rate has a positive effect on enterprise creation in the service sector, while it has a negative effect in the manufacturing sector. And a high level of wages weakens the possibilities of enterprise creation in both sectors, this effect being even more important for enterprises in the service sector. (Khalil Salman \& al., 2013) employ the random-effects negative binomial regression model (RENBM) to test the relationship between macroeconomic factors and the birth of new enterprises. They consider a sample of 135 panel-data observations, taken from 27 countries in the European Union (EU) during the period 2004-2008. They found that the birth of new enterprises is positively related to the growth of GDP, inflation, and openness, and is negatively related to unemployment. The results also show that expenditure on research and development (R\&D) has a significant positive effect on the emergence of new enterprises. Using an annual panel of US states over the period 1982-2014, (Gourio \& al., 2016) estimated the response of macroeconomic variables to a shock to the number of new firms. They find that these shocks have significant effects that persist for many years on real GDP, productivity, and population.

\section{METHODOLOGY}

\subsection{Data and Variable Selection}

For our study, we used a heterogeneous panel data approach for our empirical estimation of the regression model. Our data collection consists of 73 developing countries which was gathered from World Development Indicators (WDI) and was published by World Bank for the period of 2006-2018. We selected New Businesses Registered as a dependent variable. The exogenous variables are: i) GDP (constant 2010 US\$); ii) Unemployment; iii) Vulnerable employment; iv) Population growth; v) Consumer price index; vi) openness (Table 1).

Table 1. Description of variables

\begin{tabular}{|cc|}
\hline Variables & Description \\
\hline $\begin{array}{c}\text { Dependent variable } \\
\text { NewFirms } \\
\text { Independent variables }\end{array}$ & New businesses registered (number) \\
\hline GGDPpc & GDP per capita growth (annual \%) \\
GPOP & Population growth (annual \%) \\
VulEmp & Vulnerable employment, total (\% of total employment) \\
UnEmp & Unemployment, total (\% of total labor force) \\
OPEN & Trade (\% of GDP) \\
CPI & Consumer price index (2010 100$)$ \\
\hline
\end{tabular}

\subsection{Estimation}

Based on the theoretical and empirical literature review and selected variables, we define the following equation used later for estimation:

$$
\operatorname{lnNewFirms}_{i t}=\alpha+\sum_{j=1}^{6} \beta_{j} X_{i t}+\varepsilon_{i t}+\theta_{t}+u_{i, t}
$$

Where $\alpha$ is the constant, $i$ are the indices for the country, $t$ is for the year, $X_{i t}$ the explanatory or independent variables, $\beta_{j}$ the coefficient of individual independent variable. After including exogenous variables, we find this equation:

$$
\begin{aligned}
\text { lnNewFirms }_{i t}= & \alpha+\beta_{1} \text { GDPpc }_{i t}+\beta_{2} \text { Gpop }_{i t}+\beta_{3} \text { VulEmp }_{i t}+\beta_{4} \text { UnEmp }_{i t}+\beta_{5} \text { CPI }_{i t} \\
& +\beta_{6} \text { Open }_{i t}+\varepsilon_{i t}+\theta_{t}+u_{i, t}
\end{aligned}
$$


By using the time fixed effect dummy, the estimation model accounts for the aggregate (time series) trends to reduce its influence on the cross-country regression. Therefore, the approach controls the common trends in the panel data models, which may produce a spurious relationship with a high $R^{2}$ and a statistically significant relationship between the variables. Time fixed-effect dummies would also capture the structural break that may be present in the time series (Caceres \& al., 2010).

The correlation matrix presented in Table 2 also rules out the possibility of any significant multicollinearity bias and shows the general level of relationships among the variables. Since the data shows a cross-section dependency and heteroskedasticity, we need to perform two empirical techniques to mitigate these issues and produce robust standard errors. The study uses Prais-Winsten regression with correlated PCSE and system GMM estimation.

Table 2. Correlation matrix

\begin{tabular}{|c|c|c|c|c|c|c|c|}
\hline & lnNewFirms & GGDPpc & GPOP & VulEmp & UnEmp & OPEN & CPI \\
\hline InNewFirms & 1 & & & & & & \\
\hline GGDPpc & 0.0496 & 1 & & & & & \\
\hline GPOP & -0.1194 & -0.2281 & 1 & & & & \\
\hline VulEmp & -0.2255 & 0.1844 & 0.0197 & 1 & & & \\
\hline UnEmp & 0.0579 & -0.0608 & -0.2387 & -0.3071 & 1 & & \\
\hline OPEN & -0.1998 & -0.0202 & 0.0418 & -0.3838 & 0.0574 & 1 & \\
\hline CPI & 0.1600 & -0.1600 & -0.0359 & 0.0619 & -0.0038 & -0.1381 & 1 \\
\hline
\end{tabular}

The PCSE estimation assumes that disturbances are heteroskedastic and contemporaneously correlated across panels, and can handle unbalanced panel (Greene, 2012). In the GMM approach proposed by (Arellano \& Bover, 1995) and (Blundell \& Bond, 1998), the lagged values of the dependent variable are used as instruments to account for the endogeneity problem. Both first-differenced GMM and system GMM got a lot of attention in the past empirical studies. However, (Levine \& al., 2000) argued that the first-differenced method is not efficient if the sample size is small. In addition, (Bond, 2002) concluded that the estimator may be biased if data is not stationary.

While using system GMM, a higher accuracy of the estimation result can be achieved. For the reason that the method uses a higher number of instruments by system GMM makes both regression in the levels and in the first differences. Moreover, system GMM is comparatively better because when time series is close to being a random walk, the instruments in the level estimation are efficient predictors for the endogenous variables (Blundell \& Bond, 1998).

In the following sections, we will be using system GMM model:

$$
\begin{gathered}
\vartheta_{i t}=\alpha_{i}+\gamma \vartheta_{i, t-1}+\sum_{p=1}^{p} \beta_{p} Z_{i t}^{p}+\sum_{q=1}^{q} \beta_{q} Z_{i t}^{q}+\sum_{r=1}^{r} \beta_{r} Z_{i t}^{r}+\epsilon_{i t} \\
\epsilon_{i t}=v_{i t}+e_{i t}
\end{gathered}
$$

In this model, we define the following:

$\vartheta_{i t}$ : indicates the New businesses registered of country $i$ at time $t$.

$\alpha_{i}$ : indicates the constant term

$\gamma \vartheta_{i, t-1}$ : represents the lag value of new businesses registered of country $i$ at time $t$.

$Z_{i t}:$ consists of the predictor variables of country $i$ at time $t$.

$\epsilon_{i t}:$ is the error-term of country $i$ at time $\mathrm{t}$. 
In addition, the unobserved growth specific factors and the idiosyncratic errors are $v_{i t}$ and $e_{i t}$, respectively. According to (Blundell \& Bond, 1998) and (Bond, 2002), the model also takes the following assumptions:

$$
\left\{\begin{array}{l}
E\left(v_{i t}, v_{i s}\right)=0 \text { for } i=1, \ldots, n \text { and } t \neq s \\
E\left(\vartheta_{i t}, v_{i s}\right)=0 \text { for } i=1, \ldots, n \text { and } t=2, \ldots, T
\end{array}\right.
$$

Finally, we used the system GMM estimation as it improves the precision of the model while reducing small sample bias.

\section{RESULTS AND DISCUSSIONS}

In this section, we are going to present our results. First, we determine which model provides the best fit for our data. Next, we identify and discuss significant predictors. The results of estimations are reported in Table 3.

Table 3. Results from estimations

\begin{tabular}{|c|c|c|}
\hline Dependent variable: $\operatorname{lnNewFirms}$ & PCSE estimation (1) & Sys-GMM estimation (2) \\
\hline$G G D P p c$ & $0.013 * * *(0.002)$ & $0.015 * * *(0.000)$ \\
\hline$G P O P$ & $-0.081 * * *(0.000)$ & $0.001 * *(0.048)$ \\
\hline VulEmp & $-0.026 * * *(0.000)$ & $-0.001 * * *(0.004)$ \\
\hline UnEmp & $-0.019 * *(0.046)$ & $-0.015 * * *(0.000)$ \\
\hline OPEN & $-0.008 * * *(0.000)$ & $-0.003 * * *(0.000)$ \\
\hline$C P I$ & $0.009 * * *(0.000)$ & $0.0009 * * *(0.000)$ \\
\hline L1.lnNewFirms & - & $0.763 * * *(0.000)$ \\
\hline Constant & $9.570 * * *(0.000)$ & $2.640 * * *(0.000)$ \\
\hline$R^{2}$ & 0.794 & - \\
\hline No. of observation & 842 & 773 \\
\hline No. of instruments & - & 79 \\
\hline Arellano-Bond test for $\operatorname{Ar}(1)(\operatorname{Pr}>\mathrm{z})$ & - & 0.001 \\
\hline Arellano-Bond test for $\operatorname{Ar}(1)(\operatorname{Pr}>\mathrm{z})$ & - & 0.610 \\
\hline Hasen test of overidentifying restrictions & - & 0.473 \\
\hline
\end{tabular}

Notes: Standard error in the parenthesis. $* * *, * * *$ significant at $10 \%, 5 \%$ and $1 \%$ levels, respectively.

According to the results obtained from model (1), we can state that the real GDP per capita has a positive and significant impact on enterprise creation. Meaning that an increase in real GDP per capita in the long run, leads to an increase in the number of enterprises created. The demand effect expressed through this variable should be interpreted in the sense of the evolution of purchasing power. This is because the population growth rate variable, which is supposed to express the variation in market size, have a negative effect on enterprise creation.

According to model (2), the growth of GDP per capita has the effect of increasing the number of enterprises by $1.5 \%$ per year. At the $5 \%$ threshold, population growth positively and significantly influences enterprise creation. Trade openness has a small influence on the creation of new enterprises, as the opening of a new market is not always a positive factor. This variable can increase competition, and consequently, decrease the number of new enterprises by $0.3 \%$ per year. Inflation on the other hand, represented by the consumer price index, has a weak positive effect which increases the number of new enterprises by $0.09 \%$ per year. 
Our results indicate that unemployment and employment vulnerability have small negative effects on new enterprises creation, leading to a reduction in the number of new enterprises by $1.5 \%$ and $0.1 \%$, respectively per year. Contrary to our findings, literature review and macroeconomic theory suggests that higher unemployment can lead to a decrease in aggregate demand, which in turn puts downward pressure on the number of new business start-ups. Our study highlighted the characteristics and factors involved in an unfortunate economic atmosphere, in our case the important role of high unemployment or high employment vulnerability in enterprises creation. Long term unemployment has a large effect on enterprise creation, which suggests that for many entrepreneurs, creating an enterprise is the result of escaping unemployment rather than exploiting business opportunities.

In terms of demand or purchasing power, governments and public authorities should implement reforms and regulations to effectively stimulate consumption and domestic demand. These reforms should target low-income families by improving their employment conditions and their inclusion through employment guidelines and policies. As the financial constraint has been identified in previous studies on the subject as one of the major obstacles to enterprise creation and entrepreneurship development, as such governments should invest in financial policies to allow access to financial aids in order to promote business and the economy.

\section{CONCLUSION}

The study examines the influence that the growth GDP per capita has on the new businesses registered on our data collection resuming developing countries from period of 2006-2018. In the analysis, both statics and dynamic panel estimations techniques have been employed. The results obtained in this paper are in line with the theoretical framework and validate our hypothesis with making an exception to both unemployment rate and employment vulnerability.

These outcomes revealed that foremost economic growth, translated in terms of real gross domestic product per capita, and in terms of variation in demand (by improving or increasing purchasing power), has proved to be a positive determining factor in the creation of enterprises. Moreover, the population growth rate and inflation, while contributing positively to the creation of new enterprises, did not produce the effect that would have been expected, given the relatively low elasticity.

These results, although relevant to the reality, are limited by the fact that a more refined analysis of the determinants of enterprise creation based on microeconomic or survey data at the individual level was not possible. The unavailability of such data did not allow us to highlight capture of other determinants such as those related to attitudes towards risk, age, gender, education level, ability to identify and exploit opportunities, and to culture.

Furthermore, for an ecosystem to be able to promote enterprise creation, it is crucial for governments and public authorities to invest and implement financial aid and policies for very small enterprises, small and medium-sized enterprises and new start-ups. Such policies should include both financial and non-financial support. In-kind support should include access to training services that meet potential entrepreneurs' needs and improve their capabilities, such as financial management, technical support and business strategy. 
In addition, future reforms should emphasize the simplification of administrative procedures by fighting bureaucracy and corruption and encourage the banking system to become more involved in promoting new businesses, in the form of credit, venture capital and various forms of aid and support. The main issue is to facilitate the work of the future entrepreneur in the official economy and thus reduce the informal economy.

The creation is an important vector for the creation of employment and wealth. The creation of a business is itself preceded by the intention to create. However, it represents the best predictor of the act of entrepreneurship. Government initiatives will only have an impact on business creation if they influence attitudes, behaviors and intentions. We seek through our work to encourage and participate in economic development by promoting the entrepreneurial spirit.

\section{REFERENCES}

Arellano, M. and Bover, O. (1995), Another look at the instrumental variable estimation of error-components models, Journal of Econometrics, 68(1), 29-51.

Audretsch, D.B., Fritsch, M. (1994), The Geography of Firm Births in Germany, Regional Studies, 28(4), 359-365.

Blundell, R. and Bond, S. (1998), Initial conditions and moment restrictions in dynamic panel data models, Journal of Econometrics, 87(1), 115-143.

Bond, S.R. (2002), Dynamic panel data models: a guide to micro data methods and practice, Portuguese Economic Journal, 1(2), 141-162.

Braunerhjelm, P. (2007). Academic entrepreneurship: Social norms, university culture and policies. Science and Public Policy, 34(9), 619-631.

Caceres, C., Corbacho, A. and Medina, L. (2010). Structural breaks in fiscal performance: did fiscal responsibility laws have anything to do with them?, IMF working paper, Washington, DC, 10 November.

Carree, M.A. (2006). Does unemployment affect the number of establishments? A regional analysis for US States, Regional Studies, Vol. 36, 389-398.

Choi, Y.R., Phan, P.H. (2006). The influences of economic and technology policy on the dynamics of new firm formation, Small Business Economics, 26, 493-503.

Fritsch, M., Falck, O. (2007). New business formation by industry over space and time: a multi-dimensional analysis, Regional Studies, 41(2), 157-172.

Froyen, R.T. (2013). Macroeconomic theories and policies, $10^{\text {th }}$ ed., England: Pearson Global.

Levine, R., Loayza, N. and Beck, T. (2000). Financial intermediation and growth: causality and causes, Journal of Monetary Economics, 46(1), 31-77.

Gourio, F., Messer, T. and Siemer, M. (2016). Firm Entry and Macroeconomic Dynamics: A State-Level Analysis. American Economic Review, 106(5):214-18.

Greene, W.H. (2012). Econometric Analysis, $7^{\text {th }}$ ed., Prentice Hall, New York, USA.

Keeble, D., Wever, E. (Eds.) (1986). New firms and Regional Development in Europe, Croom Helm, New Hampshire.

Knight, F. K. (1921). Risk, Incertainty and profit, New York: Houghton Mifflin.

Koellinger, P. D., Thurik, A.R. (2009). Entrepreneurship and the business cycle, Tinbergen Institute Discussion Paper, 09-032/3, Tinbergen Institute.

Masuda T. (2006). The determinants of latent entrepreneurship in Japan, Small Business Economics, 26(3), 227-240.

Otsuka, A. (2008). Determinants of new firm formation in Japan: a comparison of the manufacturing and service sectors, Economic Bulletin, 18(4), 1-7. 
Oxenfeldt, A.R. (1943). New firms and free enterprise: pre-war and post-war aspects, Washington: American Council on Public Affairs.

Reynolds, P.D., Storey, D.J. (Eds.) (1993). Local and regional characteristics affecting small business formation: A cross national comparison, Paris: European CommissionOECD/WKSUM01.

Salman, A.K., Zampatti, D., Shukur, G. (2013). Macroeconomic Determinants, Innovation and the Birth of New Firms: Negative Binomial Regression Approach: Negative Binomial Regression Approach, International Journal of Economics and Finance, 5(11), 72-81.

Santarelli, E., Carree, M., Verheuls, I. (2009). Unemployment and firm entry and exit: an update on a controversial relationship, Regional Studies, 43(8), 1061-1073.

Sutaria, V., Hiks, D.A. (2004). New firm formation: Dynamics and determinants, The Annals of Regional Sciences, 38(2), 241-262.

Tambunan, T. (1994). Rural small-scale industries in developing region: sign of poverty or progress? A case study in Ciomas Subdistrict, West-Java Province, Indonesia, Entrepreneurship \& Regional Development, 6, 1-13.

Thurik, A.R., Carree, M.A., Stel, A.V., Audretsch, D.B. (2008). Does self-employment reduce unemployment?. Journal of Business Venturing, Vol. 23, 673-686.

Wenekers, S., Stel, A.V., Thurik, R., Reynolds, P. (2005). Nascent entrepreneurship and the level of economic development, Small Business Economics, 24(3), 293-309. 